\title{
Using Probe Data Analytics for Assessing Freeway Speed Reductions During Rain Events
}

\author{
W. Logan Downing \\ Purdue University \\ wdownin@purdue.edu \\ Howell Li \\ Purdue University \\ howell-li@purdue.edu \\ Bill Morgan \\ Purdue University \\ morga185@purdue.edu \\ Cassandra McKee \\ Purdue University \\ mckee23@purdue.edu \\ Darcy M. Bullock* \\ Purdue University \\ 207 S Martin Jischke Dr., 204A \\ West Lafayette, IN 47906 \\ (765) 494-2226 \\ darcy@purdue.edu \\ *Corresponding author
}

August 1, $2018^{1}$

\footnotetext{
${ }^{1}$ Submitted to the Transportation Research Board (TRB) 98th Annual Meeting on August 1, 2018. Presented on January 14, 2019 at TRB in Washington, D.C.
} 


\begin{abstract}
Rain impacts roadways such as wet pavement, standing water, decreased visibility, and wind gusts and can lead to hazardous driving conditions. This study investigates the use of high fidelity Doppler data at $1 \mathrm{~km}$ spatial and 2-minute temporal resolution in combination with commercial probe speed data on freeways.

Segment-based space-mean speeds were used and drops in speeds during rainfall events of $5.5 \mathrm{~mm} /$ hour or greater over a one-month period on a section of four to six-lane interstate were assessed. Speed reductions were evaluated as a time series over a 1-hour window with the rain data. Three interpolation methods for estimating rainfall rates were tested and seven metrics were developed for the analysis. The study found sharp drops in speed of more than $40 \mathrm{mph}$ occurred at estimated rainfall rates of $30 \mathrm{~mm} /$ hour or greater, but the drops did not become more severe beyond this threshold. The average time of first detected rainfall to impacting speeds was 17 minutes.

The bilinear method detected the greatest number of events during the 1-month period, with the most conservative rate of predicted rainfall. The range of rainfall intensities were estimated between 7.5 to $106 \mathrm{~mm} /$ hour for the 39 events. This range was much greater than the heavy rainfall categorization at $16 \mathrm{~mm} /$ hour in previous studies reported in the literature. The bilinear interpolation method for Doppler data is recommended because it detected the greatest number of events and had the longest rain duration and lowest estimated maximum rainfall out of three methods tested, suggesting the method balanced awareness of the weather conditions around the roadway with isolated, localized rain intensities.
\end{abstract}

Keywords: probe data, commercial vehicle, high-fidelity radar data, doppler, rain intensity, backof-queue crash, impact duration, recovery time 


\section{Table of Contents}

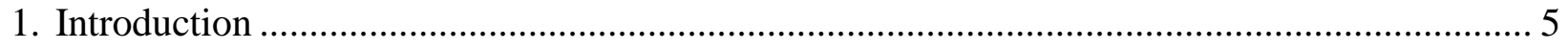

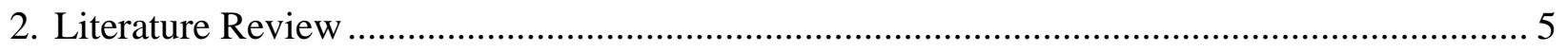

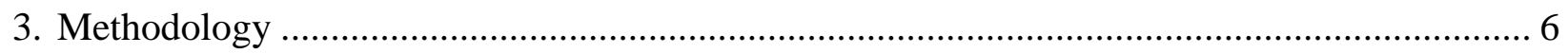

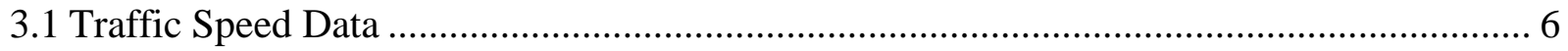

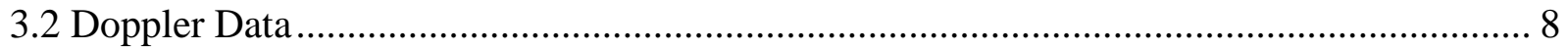

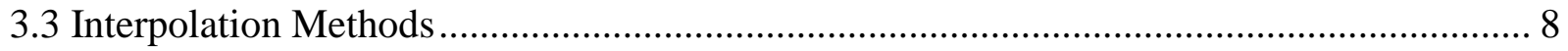

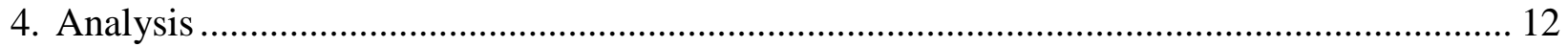

4.1 Performance Metrics for Assessing Rain Impact.......................................................... 12

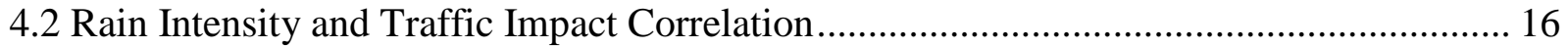

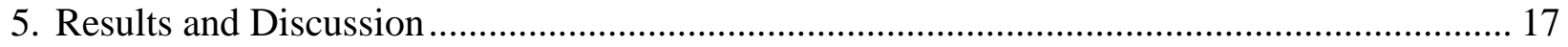

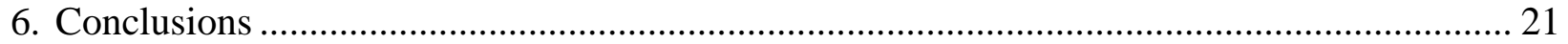

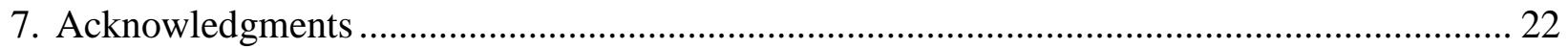

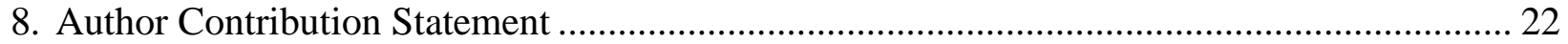

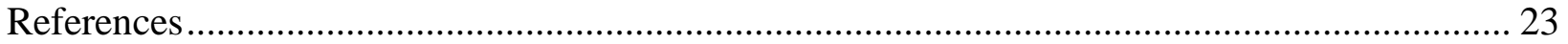


Figure List

Figure 1. Probe data segmentation.......................................................................................... 7

Figure 2. Graph of grid, roadway segment center point, buffer area, and cells used for interpolation

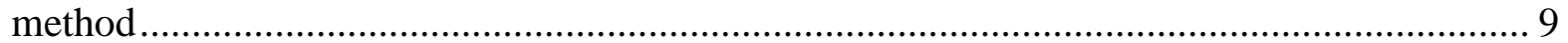

Figure 3. A simple bilinear interpolation example ....................................................... 9

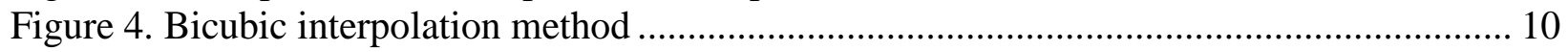

Figure 5. Three methods for interpolating rain intensity, with traffic speed overlay, I-65 northbound at mile marker 130, June 9, 2018 ................................................................. 11

Figure 6. Radar overlay on traffic speed condition map on June 9, 2018 ................................ 12

Figure 7. Process for construction of $+/-30$ minute time windows and generating the seven metrics

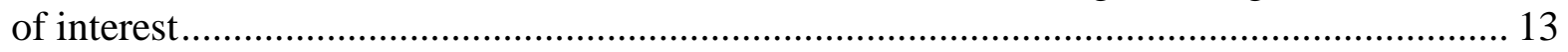

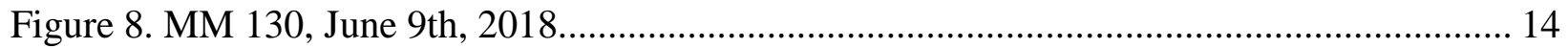

Figure 9. Rainfall rate versus peak delta speed using bilinear interpolation ............................. 17

Figure 10. Four rain storm use cases overlaying traffic and weather data ................................ 20

\section{Table List}

Table 1. Statistics for interpolation methods 14

Table 2. I-65 Weather/speed drop events detected using the bilinear method, MM 122-171, 6:3020:30 in June 2018 (events highlighted in orange are likely related to congestion) ............. 15

Table 3. Crashes during June along I-65 between mile markers 122 and 171 .......................... 16 


\section{INTRODUCTION}

According to the Federal Highway Administration (FHWA), 46\% of weather-related crashes are due to rain and $76 \%$ of crashes happen on wet pavement (1). Rainfall can affect visibility distance, pavement friction, and obstructs or submerges the roadway. A 10 year average of the data from 2004 to 2014 found that there were 573,784 crashes, 228,196 injuries, and 2,732 fatalities annually related to rain conditions alone (1). Compared to crashes due to all winter-related conditions of snow/sleet, and icy pavement conditions combined, there were 7\% more crashes, 67\% more injuries and $49 \%$ more fatalities annually from rain (1). While costs of types of crashes vary nationally, a rough estimate for property damage alone using the default comprehensive crash unit cost amounts to over $\$ 4$ billion a year (2).

Recent developments of the National Weather Service's (NWS) Next-Generation RADAR (NEXRAD) network and improved data distribution interfaces have now enabled high-temporal and spatial fidelity data to be accessible to the public $(3,4)$. In addition, developments in commercially-available crowdsourced probe vehicle data have enabled agencies and practitioners to leverage traffic speed information captured from smartphones, fleet, embedded vehicle telematics and GPS units to make tactical decisions in real-time, assess operational strategies, perform after-action reviews, and pro-actively monitor roadway conditions $(5,6,7,8,9)$. There are new opportunities to synergize these technologies and leverage the high-fidelity datasets to engage in high-impact research that can predict and potentially mitigate rain-related incidents.

\section{LITERATURE REVIEW}

Previous studies correlating traffic impacts with rainfall events make use of in-pavement loop (11, $12,13)$, or mounted radar detectors (13) at specific points along the roadway, and some studies have used probe data to track speeds but only on urban arterials $(14,15)$. In terms of weather data, many rainfall estimates used in these studies were localized, such as from Road Weather Information System (RWIS) stations, or had relatively low spatial and temporal resolution such as Automated Surface Observation System (ASOS, 10), or from nearby weather stations such as an airport $(11,12,13,14,15)$ that gave rainfall rates in hourly increments over large areas. Due to the coarse nature of these data sources, rainfall intensities were typically categorized into gradations such as light, moderate, and heavy.

Early research by Ivey, et al. have concluded that speeds were reduced during heavy rainfall at intensities of $25 \mathrm{~mm} /$ hour or more due not only to reduced visibility, but also from hazardous passing maneuvers and the existing speed of traffic (16). While there were many studies that have focused on reductions in capacity close to at-capacity conditions, results regarding how much speed is reduced during free-flow conditions due to rain vary across studies. The Highway Capacity Manual suggests reductions of speed in free-flow traffic in the range of $4.8 \%$ to $6.4 \%$ in heavy rain (17). Maze et al. estimates that heavy rain reduces roadway capacities by $14 \%$ to $15 \%$ (18). Ibrahim and Hall estimated speeds dropped about $1.2 \mathrm{mph}$ in light rain and 3.1 to $6.2 \mathrm{mph}$ in heavy rain in uncongested conditions (11), while Brilon and Ponzlet found speed reductions in wet conditions were $5.9 \mathrm{mph}$ in two-lane sections and $7.5 \mathrm{mph}$ in three-lane sections of roadway (12). Rakha, et al. estimated reductions of free-flow speeds of $2 \%$ to $3.6 \%$ in light rain conditions of 0.1 $\mathrm{mm} /$ hour and $6 \%$ to $9 \%$ in heavy rain conditions of $16 \mathrm{~mm} /$ hour (13) but did not provide estimates above this rate. Angel, et al. found speed reductions of $2.1 \mathrm{mph}$ in light rain (less than 2.8 $\mathrm{mm} /$ hour), $3.9 \mathrm{mph}$ in moderate rain, (2.8 to $7.6 \mathrm{~mm} /$ hour), and $4.1 \mathrm{mph}$ in heavy rain (greater 
than $7.6 \mathrm{~mm} /$ hour) but noticed different effects of heavy during the morning and evening commutes (19).

Few studies have investigated methods to improve the resolution of weather data for traffic impact analysis. Research by Jung, et al. used the inverse-squared method to better approximate rainfall intensity using three close-by weather stations at reporting intervals of 15-minutes but mentioned few data sources were available at the time to provide finer, minute-based measurements (20). Finally, Omaranian, et al. employed a high spatial resolution grid of $4 \mathrm{~km}$ square to estimate crash risk but did not examine the effects on speed (21). Recent research have emphasized the need for high spatial and temporal fidelity data to identify locations of unexpected sharp decreases in speed that affect motorist safety $(22,23)$. These locations have been shown to have increased crash rates by a factor of 24 compared to uncongested, free-flowing conditions.

\section{METHODOLOGY}

\subsection{Traffic Speed Data}

In this study, traffic speed data was obtained from INRIX. The provider aggregates multiple sources of fleet, GPS, smartphone and telematics data into representative minute-by-minute average speeds over segments of roadway at nominally $1 \mathrm{~km}$ in length (9). The focus was on warmweather rain precipitation events in central Indiana on I-65 from mile marker 122 to 171 . The study area consists of four to six-lane sections with 12' shoulders, with speed limits of 65 and $70 \mathrm{mph}$. The area is shown in Figure 1a and a distribution of segment lengths are shown in Figure 1b.

Data from overnight periods were excluded due to two reasons: visibility conditions affecting driver behavior, and data penetration. INRIX provided a metric of whether the source of data came from real-time sources, historical data, or posted speed limit where neither of the first two were available. For this study, only real-time sources from daylight hours of 6:30 am to 8:30 pm were used. For each segment, consecutive space-mean speed values were scanned and any drop in speed below $50 \mathrm{mph}$ and a rain intensity value of over $5.5 \mathrm{~mm} /$ hour within the consecutive interval was flagged for examination. The speed threshold thus requires the preexisting traffic conditions to be uncongested. 


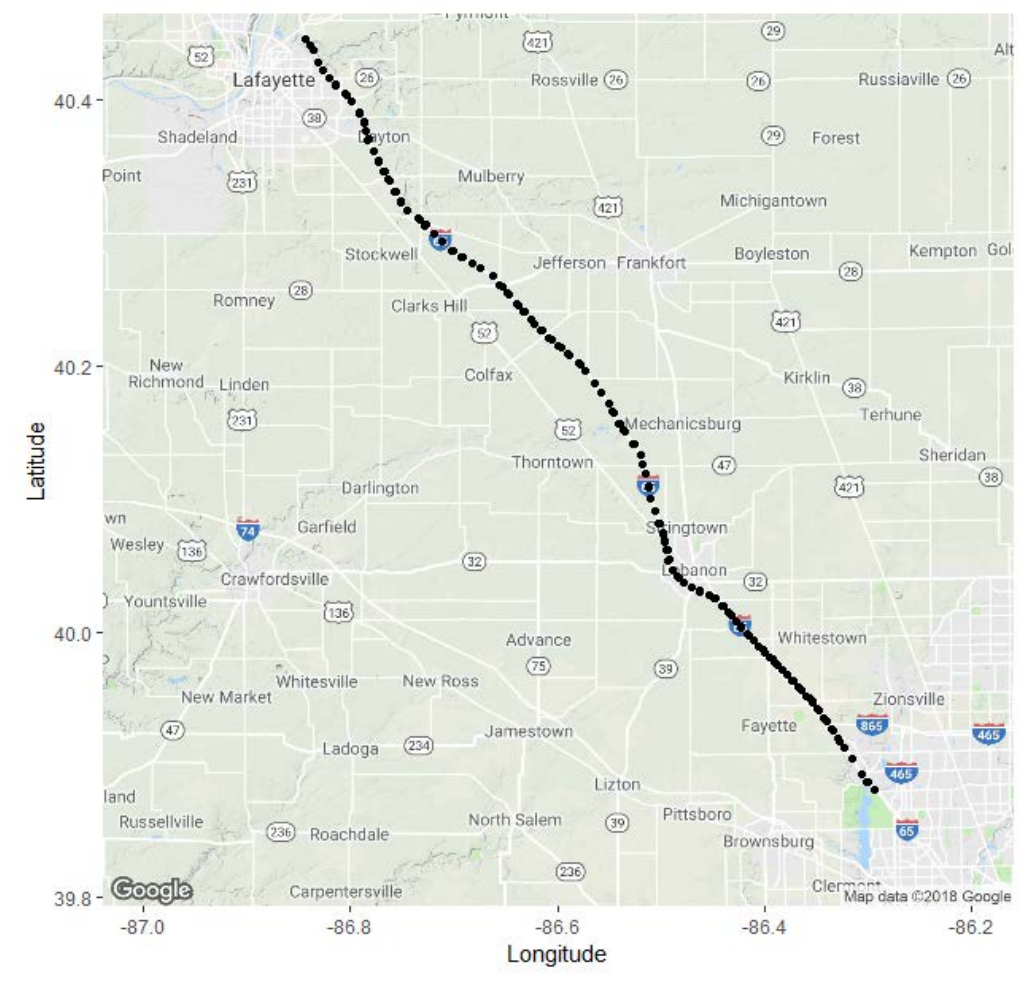

(a) Segments of interest on I-65

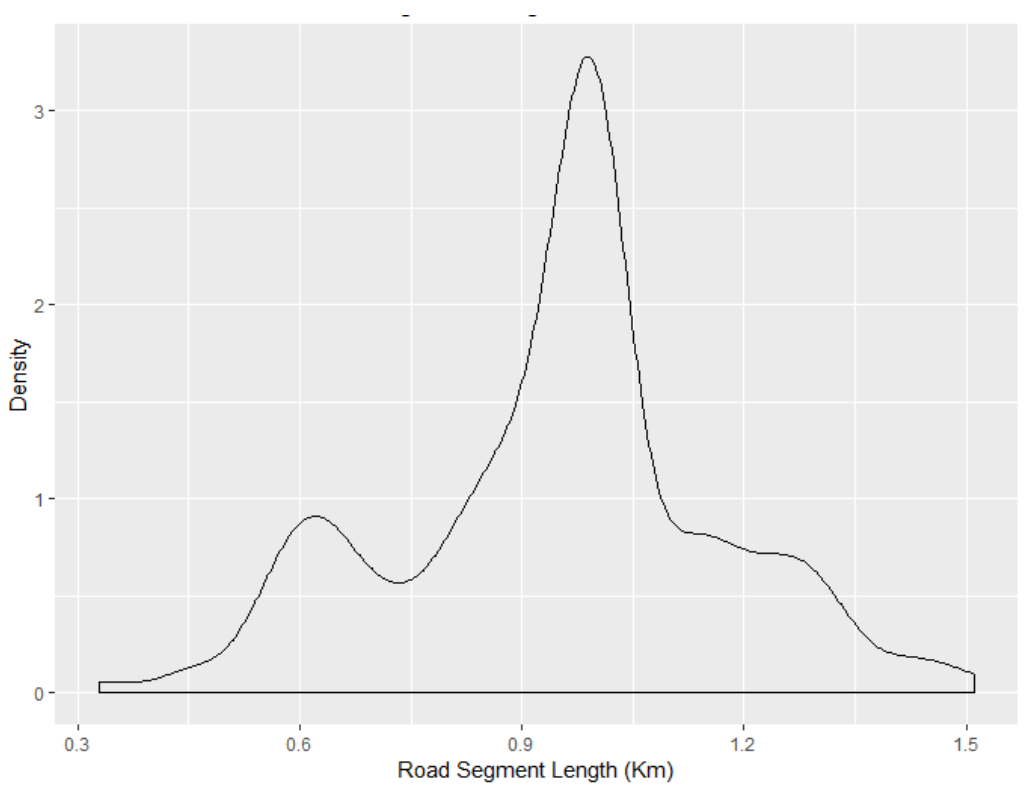

(b) Segment length distribution

Figure 1. Probe data segmentation. 


\subsection{Doppler Data}

NEXRAD Doppler weather data was obtained through a dataset known as the MultiRADAR/Multi-Sensor System (MRMS) (4) curated by the National Severe Storms Laboratory (NSSL) alongside to determine rainfall intensity at the road segment level. The provider makes quality controlled logarithmic reflectivity at the lowest possible vertical level available through a variable called Seamless Hybrid Scan Reflectivity (SHSR) (24). SHSR is often used to calculate surface precipitation rates.

The Doppler data used in this study provides gridded weather data at a $1 \mathrm{~km}$ square resolution and a temporal resolution of two minutes. There are approximately 102,500 grid points in the dataset for the state of Indiana and approximately 16,000 grid points in the area of interest for the study. For the month of June, approximately 3.3 million records were processed. Prior to using the reflectivity value to estimate rainfall intensity by interpolation, it was necessary to convert from logarithmic reflectivity to linear reflectivity by the following equation (25). Big Z denotes logarithmic reflectivity while little z denotes linear reflectivity.

$$
Z=10 \times \log _{10}(z)
$$

Equation 1

Rearranged for linear reflectivity, the equation becomes the following.

$$
z=10 \frac{Z}{10}
$$

A $5 \mathrm{~km}$ buffer of Doppler grid points were used for the analysis to allow for a window around each segment that was representative of the surrounding environment. The surrounding Doppler grid points were used to perform three methods of interpolation.

\subsection{Interpolation Methods}

Each road segment was assigned an approximate center point using SQL to assign a rainfall intensity value to the segment based on three interpolation methods, nearest neighbor interpolation, bilinear interpolation, and bicubic interpolation. These methods rely on the surrounding weather data to assign an estimated Doppler reflectivity value to the road segment. All three methods and their surrounding grid points can be seen in Figure 2. 


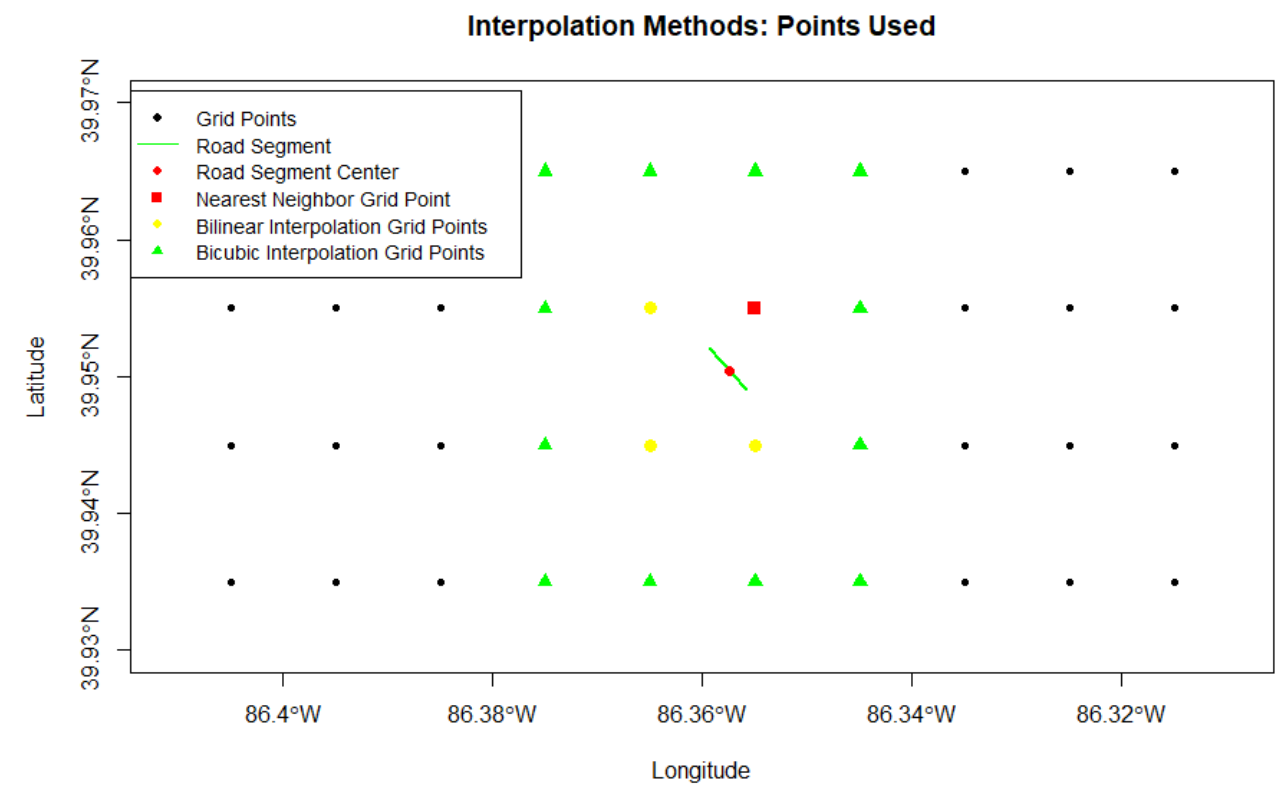

Figure 2. Graph of grid, roadway segment center point, buffer area, and cells used for interpolation method.

Nearest neighbor interpolation is the simplest of the three methods and relies on a single weather data point. The closest data point to the road segment in question is calculated and then used to assign a reflectivity value to the road segment's center point.

Bilinear interpolation is a little more involved than nearest neighbor but still relatively simple. Bilinear interpolation makes use of linear interpolation over multiple steps. Consider the value halfway between one and ten as five. Bilinear interpolation makes use of this process using the four data points surrounding a point of interest. Linear interpolation is applied to the top two data points and the bottom two data points separately. Following the two separate linear interpolations, a third linear interpolation is carried out to determine the point of interest. The figure below provides an example of this process in the same manner that is used for this study. An example for bilinear interpolation is presented in Figure 3.

\begin{tabular}{|l|l|l|l|l|}
\hline 40 & & & & 30 \\
\hline & & & & \\
\hline & & & $x$ & \\
\hline & & & & \\
\hline 40 & & & & 20 \\
\hline
\end{tabular}
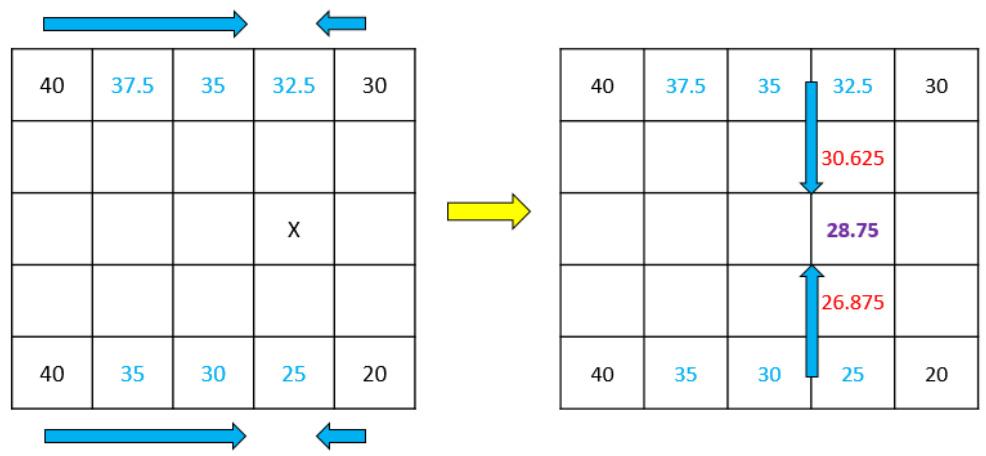

Figure 3. A simple bilinear interpolation example.

Bicubic interpolation, is more involved than bilinear interpolation. Bicubic interpolation extends the number of data points used in the interpolation process to sixteen as seen in Figure 2 
and Figure 4. Bicubic interpolation uses the extra data points to fit cubic splines between each data point. The result tends to be a smoother interpolation. This study makes use of the R package "Akima" (26) to carry out the bilinear and bicubic interpolation.
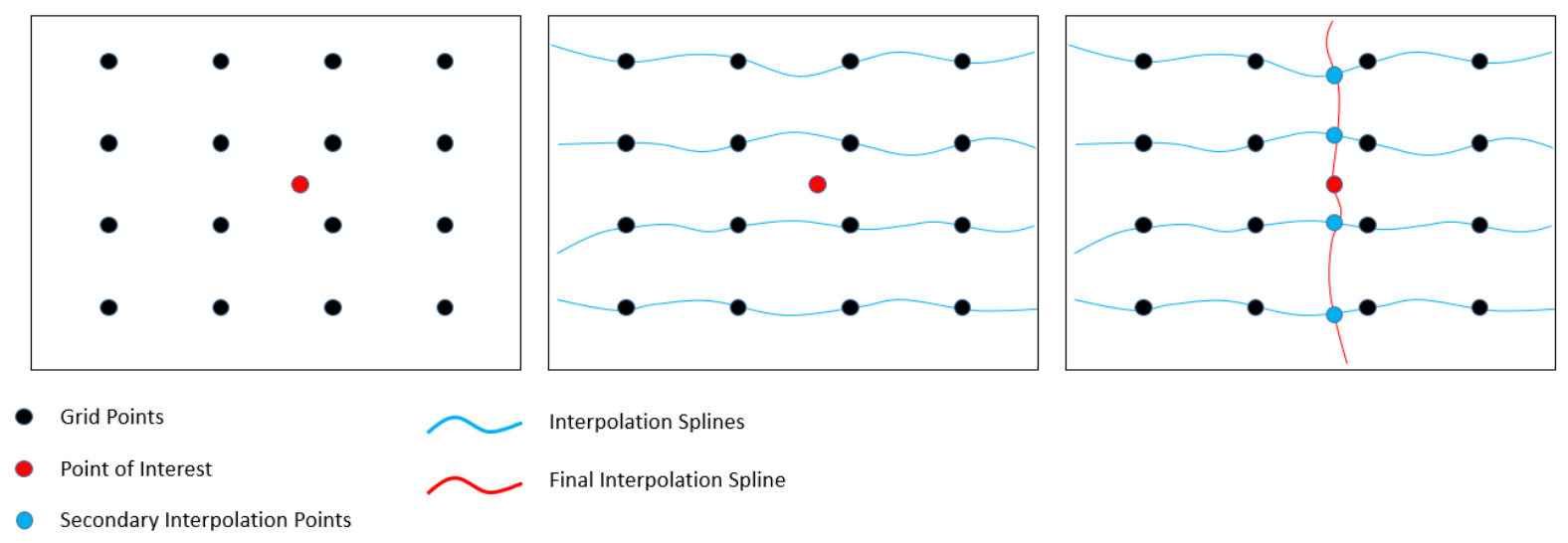

Figure 4. Bicubic interpolation method.

After the interpolation is carried out and the linear reflectivity has been converted back to logarithmic reflectivity, rainfall intensity values are calculated by the following equation, which can be derived from the Palmer Z-R relationship (25).

$$
\text { Rainfall Intensity }\left(\frac{\mathrm{mm}}{\mathrm{hr}}\right)=0.036 \times 10^{0.0625 \times Z}
$$

The speed data was joined with the rainfall intensity data for storm event analysis. The combined weather/speed dataset was then subjected to a flagging algorithm intended to detect heavy localized rainfall events where no pre-existing congested traffic conditions existed. A rainfall intensity threshold of $35 \mathrm{dBz}$, or $5.5 \mathrm{~mm} /$ hour were used. Biggerstaff et al. (27) indicate $35 \mathrm{dBz}$ and above as convective rainfall that at or beyond this threshold has the greatest impact on visibility and driving conditions. One-hour windows around each flagged rainfall event were constructed and used to produce a number of statistics that include the following: delta speed, maximum rainfall intensity, impact duration, rain duration, time to impact, maximum impact time, recovery time.

It should be noted that limitations do exist in the use of Doppler reflectivity to derive rainfall intensity at any location. Reflectivity values can be affected by blockage, biological debris, hail, and many other factors which can lead to errors in the rainfall estimate. The MRMS dataset does attempt to remedy these errors through an automated quality control step (28).

Figure 5 displays an example event from June 9th, 2018, from 12:40 to 13:40. All three interpolation methods are shown. Callout i shows the time instance where traffic speeds were high and the storm had just begun. Callout ii shows the storm having modest impact at just under $\mathbf{4 0}$ $\mathrm{mm} /$ hour and the traffic speeds starting its decline to its lowest point below $40 \mathrm{mph}$. Callout iii shows as the rain tapered off, the speeds start to recover, but not as high as before the storm. There are considerations of time synchronization between the traffic data and the Doppler data as to when the storm creates the greatest impact, which from this storm was approximately 5 minutes. Figure 6a, b, and c shows the maps overlaid with the Doppler imagery and speed data of the time slices at Callout i, ii, and iii, respectively. The circles on the map at the segment locations indicate points 
where the speed drops suddenly between segments, with the reddish coloration indicating greater speed drops.

Comparing the three methods, the data suggests the nearest neighbor may produce the highest peak intensity rainfall values due to its localized nature, while the bicubic method detects heavy incoming rain earlier by considering a greater number of data points around the area of analysis. The bilinear method appears to be a good compromise between the two methods by using four closest points.

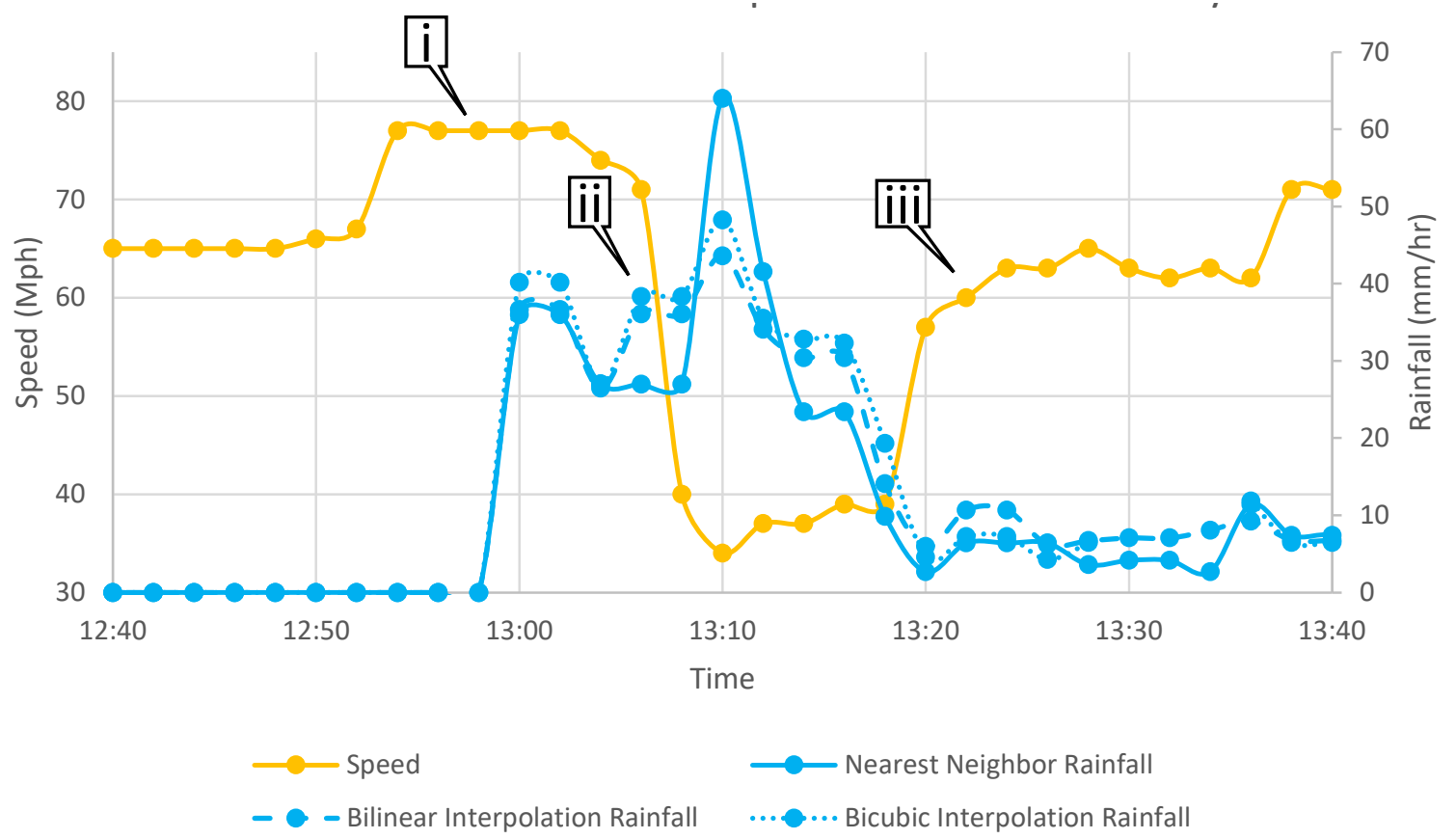

Figure 5. Three methods for interpolating rain intensity, with traffic speed overlay, I-65 northbound at mile marker 130, June 9, 2018. 


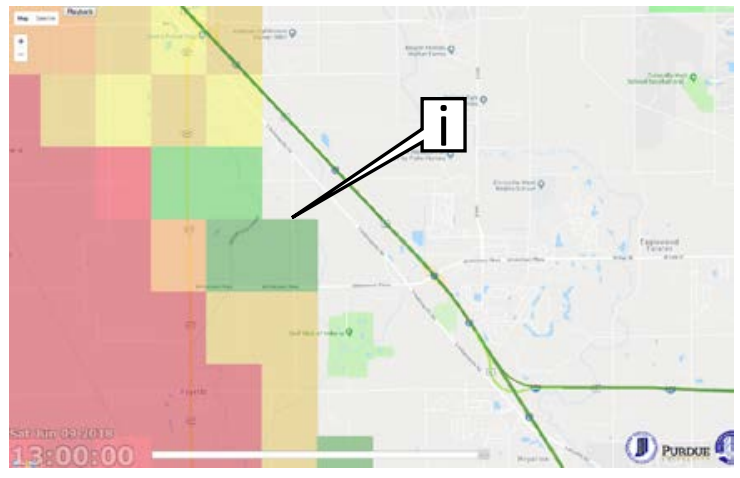

(a) Rain nears the segment $(t=13: 00: 00)$

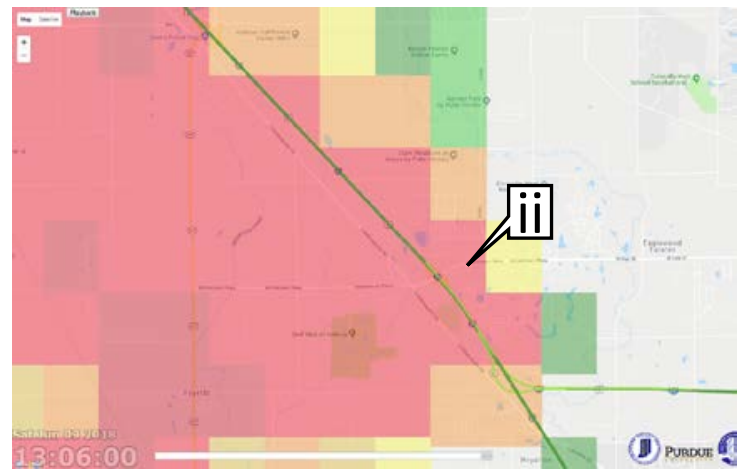

(b) speed begins to drop (t=13:06:00)p

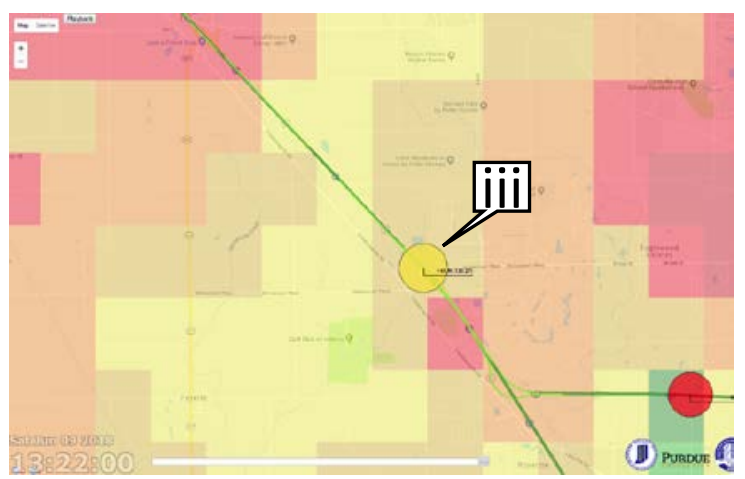

(c) Just past maximum impact point $(t=13: 22: 00)$

Figure 6. Radar overlay on traffic speed condition map on June 9, 2018.

\section{ANALYSIS}

\subsection{Performance Metrics for Assessing Rain Impact}

Seven metrics were calculated from the combined weather/speed dataset. The metrics are as follows: delta speed, maximum rainfall intensity, impact duration, rain duration, time to impact, maximum impact time, and recovery time. These statistics were calculated according to the flagging and analysis process shown in Figure 7 a, b. An example of statistics calculated for one event are shown in Figure 8. Delta speed was calculated by finding the difference between the speed when rain first passed the threshold and the minimum speed and is given in miles per hour. The maximum rainfall intensity is the maximum intensity value for the one hour window given in millimeters per hour. Impact duration was calculated by taking the difference between the time when speed returns above the threshold and the time before it first goes below the speed threshold, given in minutes. Rain duration was calculated as the number of minutes in the window that rain was above the threshold. Time to impact was calculated by finding the difference between the first time speed was below the threshold and the first time rain was above the threshold, given in minutes. Maximum impact time was calculated by finding the difference between the time when speed was at a minimum and the first time rain was above the threshold, given in minutes. Finally, recovery time was calculated by finding the difference between the time when speed returns above the threshold and the minimum speed time, given in minutes. 


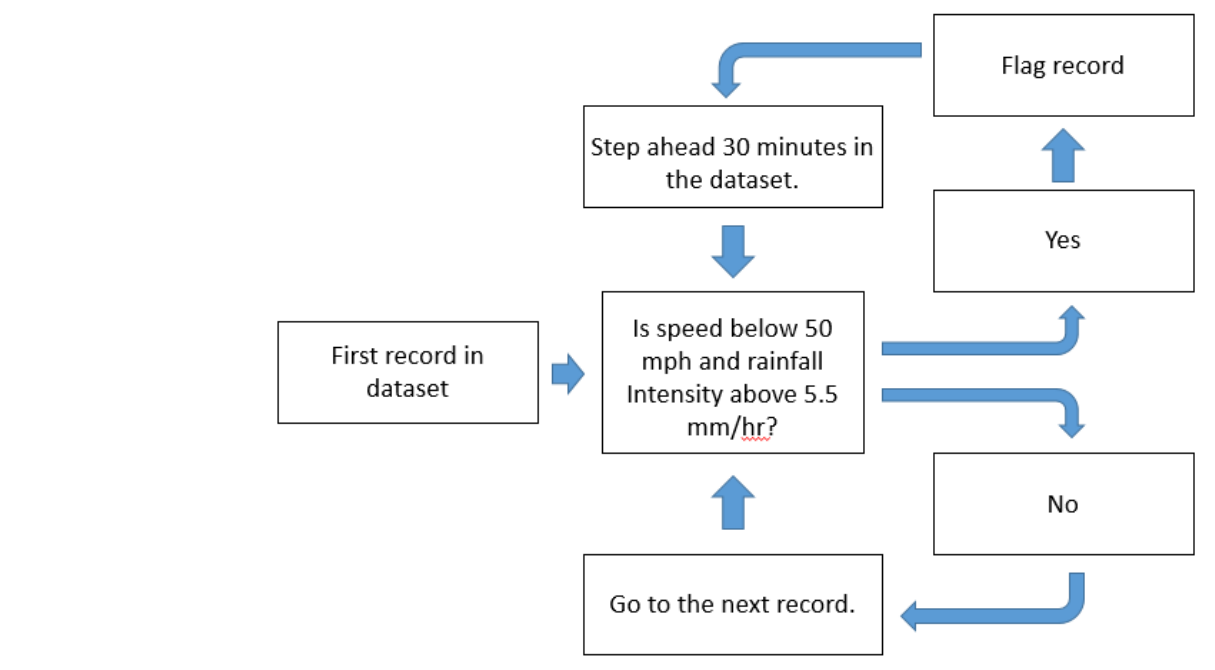

a. Flagging algorithm

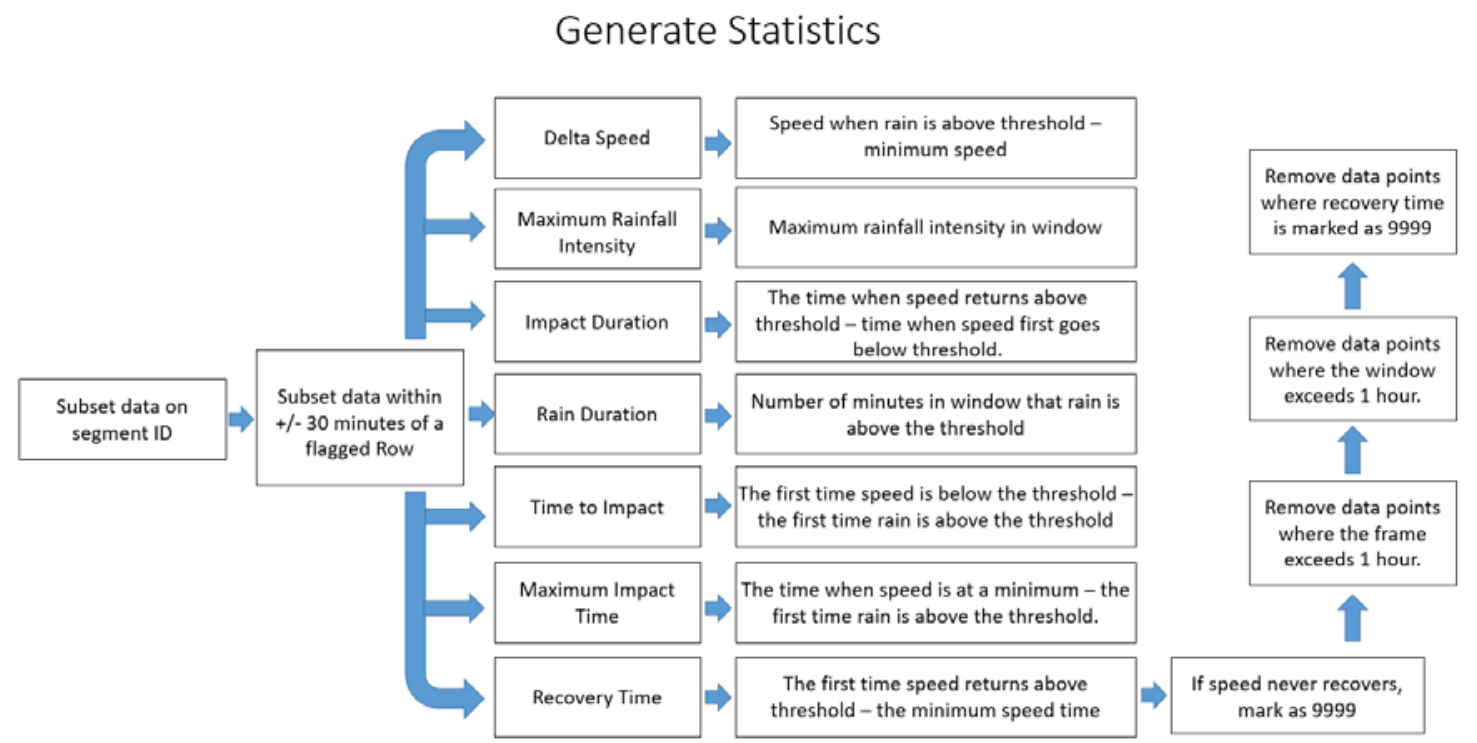

b. Statistics generation.

Figure 7. Process for construction of $+/-30$ minute time windows and generating the seven metrics of interest. 


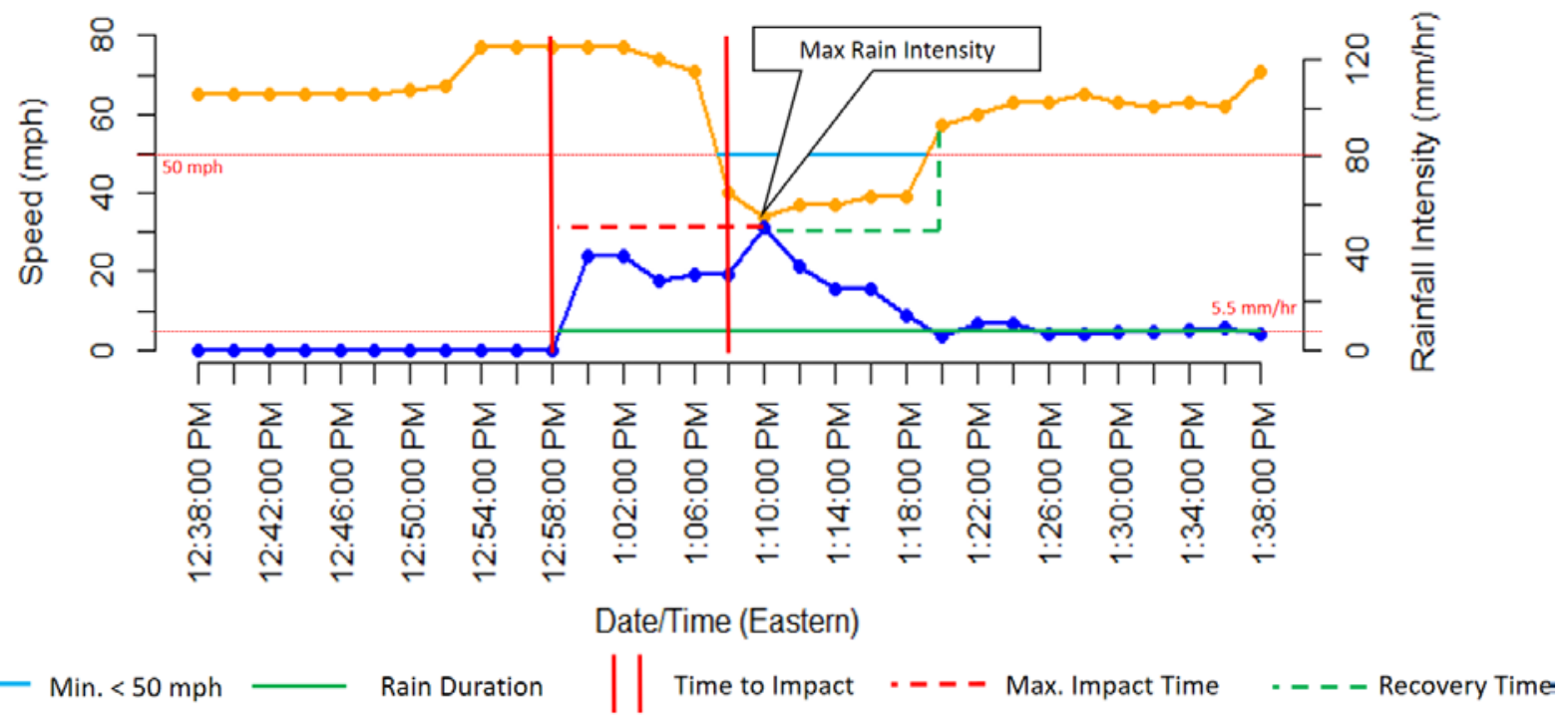

Figure 8. MM 130, June 9th, 2018.

Table 1. Statistics for interpolation methods

\begin{tabular}{ccccccc} 
Interpolation Method & $\begin{array}{c}\text { Events } \\
\text { Detected }\end{array}$ & $\begin{array}{c}\text { Most Intense Delta } \\
\text { Speed }\end{array}$ & $\begin{array}{c}\text { Max. } \\
\text { Rainfall }\end{array}$ & $\begin{array}{c}\text { Avg. } \\
\text { Duration }\end{array}$ & $\begin{array}{c}\text { Avg. Time to } \\
\text { Impact }\end{array}$ & $\begin{array}{c}\text { Avg. } \\
\text { Recovery }\end{array}$ \\
\hline Nearest Neighbor Interpolation & 32 & 54 & 57.78 & 11.25 & 16.50 & 8.06 \\
Bilinear Interpolation & 39 & 47 & 53.74 & 11.18 & 17.08 & 8.10 \\
Bicubic Inteprolation & 36 & 46 & 54.44 & 9.94 & 19.33 & 6.94
\end{tabular}


Table 2. I-65 Weather/speed drop events detected using the bilinear method, MM 122-171, 6:30-20:30 in June 2018 (events highlighted in orange are likely related to congestion)

\begin{tabular}{|c|c|c|c|c|c|c|c|c|c|c|c|}
\hline $\begin{array}{c}\text { Event } \\
\text { Number }\end{array}$ & Start MM & End MM & Time Stamp & $\begin{array}{c}\text { Peak Delta } \\
\text { Speed }\end{array}$ & $\begin{array}{c}\text { Max. } \\
\text { Rainfall } \\
\text { Intensity }\end{array}$ & $\begin{array}{c}\text { Min. }<50 \\
\text { mph }\end{array}$ & $\begin{array}{c}\text { Rain } \\
\text { Duration }\end{array}$ & $\begin{array}{l}\text { Time to } \\
\text { Impact }\end{array}$ & $\begin{array}{c}\text { Max. } \\
\text { Impact } \\
\text { Time }\end{array}$ & $\begin{array}{l}\text { Recovery } \\
\text { Time }\end{array}$ & No. Lanes \\
\hline 1 & 139.99 & 139.50 & $6 / 21 / 201816: 14$ & 26 & 51.83 & 14 & 42 & 10 & 10 & 14 & 6 \\
\hline 2 & 135.61 & 135.29 & 6/9/2018 13:20 & 28 & 38.25 & 4 & 54 & 28 & 28 & 4 & 6 \\
\hline 3 & 127.98 & 128.61 & $6 / 21 / 201816: 58$ & 47 & 30.66 & 26 & 44 & 20 & 30 & 16 & 4 \\
\hline 4 & 128.61 & 129.17 & $6 / 21 / 201816: 58$ & 46 & 46.92 & 28 & 44 & 20 & 28 & 20 & 4 \\
\hline 5 & 127.37 & 127.98 & $6 / 21 / 201816: 58$ & 40 & 36.18 & 26 & 44 & 20 & 26 & 20 & 4 \\
\hline 6 & 130.56 & 131.34 & 6/9/2018 13:08 & 44 & 41.00 & 14 & 40 & 8 & 10 & 12 & 6 \\
\hline 7 & 130.27 & 130.56 & $6 / 9 / 2018$ 13:08 & 43 & 51.03 & 14 & 40 & 8 & 10 & 12 & 6 \\
\hline 8 & 152.45 & 153.07 & $6 / 21 / 201814: 34$ & 33 & 39.65 & 8 & 24 & 6 & 8 & 6 & 4 \\
\hline 9 & 170.67 & 171.25 & $6 / 19 / 201815: 10$ & 31 & 47.69 & 14 & 32 & 14 & 24 & 4 & 4 \\
\hline 10 & 129.95 & 129.45 & $6 / 26 / 201810: 28$ & 22 & 59.39 & 10 & 42 & 14 & 18 & 6 & 6 \\
\hline 11 & 124.20 & 124.93 & $6 / 26 / 201810: 32$ & 16 & 76.42 & 4 & 32 & 12 & 12 & 4 & 4 \\
\hline 12 & 169.27 & 168.91 & 6/21/2018 9:44 & 16 & 19.38 & 8 & 28 & 12 & 12 & 8 & 4 \\
\hline 13 & 127.46 & 126.87 & $6 / 26 / 201810: 36$ & 16 & 55.44 & 4 & 36 & 20 & 20 & 4 & 4 \\
\hline 14 & 125.36 & 124.75 & $6 / 26 / 201810: 42$ & 13 & 74.51 & 4 & 34 & 24 & 24 & 4 & 4 \\
\hline 15 & 126.87 & 126.08 & $6 / 26 / 201810: 40$ & 16 & 55.84 & 6 & 36 & 24 & 24 & 6 & 4 \\
\hline 16 & 122.18 & 122.67 & $6 / 26 / 201810: 32$ & 12 & 50.55 & 14 & 28 & 8 & 16 & 6 & 4 \\
\hline 17 & 124.93 & 125.36 & $6 / 26 / 2018$ 10:34 & 20 & 75.48 & 4 & 34 & 16 & 16 & 4 & 4 \\
\hline 18 & 135.98 & 136.60 & $6 / 21 / 201816: 46$ & 30 & 62.81 & 12 & 36 & 14 & 16 & 10 & 6 \\
\hline 19 & 135.29 & 135.98 & $6 / 21 / 201816: 42$ & 40 & 59.09 & 12 & 34 & 10 & 14 & 8 & 6 \\
\hline 20 & 129.92 & 130.27 & $6 / 26 / 201810: 34$ & 15 & 50.83 & 4 & 42 & 20 & 20 & 4 & 6 \\
\hline 21 & 129.17 & 129.92 & $6 / 21 / 201816: 58$ & 28 & 69.77 & 20 & 44 & 20 & 24 & 16 & 6 \\
\hline 22 & 129.17 & 129.92 & $6 / 26 / 2018$ 10:28 & 24 & 63.45 & 16 & 42 & 14 & 22 & 8 & 6 \\
\hline 23 & 128.61 & 129.17 & $6 / 26 / 201810: 34$ & 15 & 55.88 & 6 & 42 & 20 & 22 & 4 & 4 \\
\hline 24 & 127.37 & 127.98 & $6 / 26 / 2018$ 10:34 & 16 & 55.72 & 8 & 36 & 18 & 22 & 4 & 4 \\
\hline 25 & 126.87 & 127.48 & $6 / 26 / 201810: 34$ & 14 & 55.44 & 8 & 36 & 18 & 18 & 8 & 4 \\
\hline 26 & 126.08 & 126.87 & $6 / 26 / 201810: 34$ & 13 & 55.68 & 4 & 36 & 18 & 18 & 4 & 4 \\
\hline 27 & 125.36 & 126.08 & $6 / 19 / 201816: 32$ & 15 & 51.12 & 4 & 54 & 22 & 22 & 4 & 4 \\
\hline 28 & 125.36 & 126.08 & $6 / 26 / 201810: 34$ & 23 & 69.90 & 4 & 34 & 16 & 16 & 4 & 4 \\
\hline 29 & 132.40 & 133.05 & $6 / 26 / 2018$ 10:26 & 22 & 46.37 & 6 & 46 & 16 & 18 & 4 & 6 \\
\hline 30 & 130.27 & 130.56 & $6 / 26 / 2018$ 10:34 & 15 & 64.55 & 4 & 42 & 20 & 20 & 4 & 6 \\
\hline 31 & 163.62 & 164.24 & $6 / 1 / 2018$ 15:44 & 23 & 19.84 & 14 & 8 & 4 & 10 & 8 & 4 \\
\hline 32 & 148.08 & 148.63 & 6/22/2018 18:04 & 27 & 34.95 & 18 & 54 & 22 & 30 & 10 & 4 \\
\hline 33 & 147.44 & 148.08 & $6 / 22 / 2018$ 18:12 & 26 & 29.10 & 10 & 52 & 20 & 24 & 6 & 4 \\
\hline 34 & 153.07 & 153.7 & $6 / 21 / 201814: 34$ & 26 & 49.80 & 6 & 26 & 12 & 14 & 4 & 4 \\
\hline 35 & 159.42 & 159.01 & $6 / 8 / 2018$ 17:44 & 19 & 106.44 & 4 & 30 & 28 & 28 & 4 & 4 \\
\hline 36 & 153.18 & 152.55 & $6 / 22 / 2018$ 17:56 & 20 & 52.47 & 10 & 54 & 22 & 28 & 4 & 4 \\
\hline 37 & 153.82 & 153.18 & $6 / 22 / 2018$ 17:58 & 22 & 47.42 & 8 & 54 & 24 & 24 & 8 & 4 \\
\hline 38 & 130.31 & 129.95 & 6/21/2018 17:00 & 45 & 71.79 & 28 & 44 & 22 & 32 & 18 & 6 \\
\hline 39 & 129.95 & 129.45 & $6 / 21 / 201817: 00$ & 46 & 73.34 & 28 & 44 & 22 & 28 & 22 & 6 \\
\hline
\end{tabular}


Table 1 and Table 3 shows the statistics for the three interpolation methods tested in this study. The nearest neighbor method estimated the greatest rainfall amount but also incidents with the most intense speed drops. The bilinear method detected the greatest number of events at 39, and also had the longest duration of rainfall and lowest estimated maximum rainfall. The bicubic method estimated the shortest durations of rainfall and recovery time, possibly due its bias for storms that cover a wider area, included areas that had less intense precipitation, and therefore fell below the $5.5 \mathrm{~mm} /$ hour threshold. The nearest neighbor and bilinear methods had a similar time to impact at 16.5 and 17 minutes, respectively, while the bicubic method was closer to 19 minutes. Recent studies have used 15-minute time windows for evaluating rain events which, even accounting for a 5 minute latency and driver response, suggests time-series analysis may be necessary to correlate rain time of different windows to traffic impact time at these temporal resolutions.

\subsection{Rain Intensity and Traffic Impact Correlation}

As an example, Table 2 shows a list of speed drops and performance metrics as detected from the bilinear interpolation method. The bilinear method detected the greatest number of events during the 1-month period, with the most conservative rate of predicted rainfall. The range of rainfall intensities were estimated between 7.5 to $106 \mathrm{~mm} /$ hour for the 39 events. This range was much greater than the heavy rainfall categorization at $16 \mathrm{~mm} /$ hour in previous studies (13). Periods of potential congestion are highlighted in orange. Congestion was flagged for each event if, for the same time of day and day of week one week prior, a similar reduction in speed was found at that location without precipitation. Notably, congestion events tended to have lower relative peak delta speeds when compared to the rest of the data set in Table 2. Table 3 shows two crashes that were flagged as relating to wet conditions from the Indiana crash report database for June 2018. Even though no reported crash events were connected to any of the detected speed drops, this shows that there are potentially many more hazardous wet-weather events that create near-miss situations that may go unreported. Conversely, there are also scenarios where the rainfall and speeds may not meet detection thresholds, but where crashes occur due to other factors.

Table 3. Crashes during June along I-65 between mile markers 122 and 171

\begin{tabular}{|c|c|c|c|c|c|c|c|c|c|}
\hline Date and Time & Route & Direction & $\begin{array}{c}\text { Mile } \\
\text { Marker }\end{array}$ & $\begin{array}{l}\text { Vehicles } \\
\text { Involved }\end{array}$ & $\begin{array}{l}\text { Trailers } \\
\text { Involved }\end{array}$ & $\begin{array}{c}\text { TYPE OF } \\
\text { CRASH }\end{array}$ & $\begin{array}{l}\text { Visibility } \\
\text { related? }\end{array}$ & $\begin{array}{l}\text { Loss of } \\
\text { control? }\end{array}$ & Comments \\
\hline $6 / 10 / 18$ 11:10 & 165 & $\mathrm{~S}$ & 121.2 & 1 & 0 & PDO & $\mathrm{NO}$ & YES & HYDROPLANING \\
\hline $6 / 21 / 18$ 14:51 & 165 & $\mathrm{~N}$ & 133.6 & 2 & 0 & PDO & NO & YES & HYDROPLANING \\
\hline
\end{tabular}

Figure 9 shows the relationship between maximum rainfall intensity and calculated delta speeds for the incidents detected using the bilinear method in Table 2. Events potentially related to congestion are highlighted in yellow. In general, there was no strong correlation between the rainfall intensities and delta speeds. The highest delta speeds experienced above $40 \mathrm{mph}$ tended occur at rainfall intensities of $30 \mathrm{~mm} /$ hour or greater, bounded by dashed lines. Also, there does not appear to be a strong influence of the width of the roadway with the speed drops. The majority of the speed drops were in the range of 10 to $35 \mathrm{mph}$. Four cases called out in the figure will be discussed in the next section. 


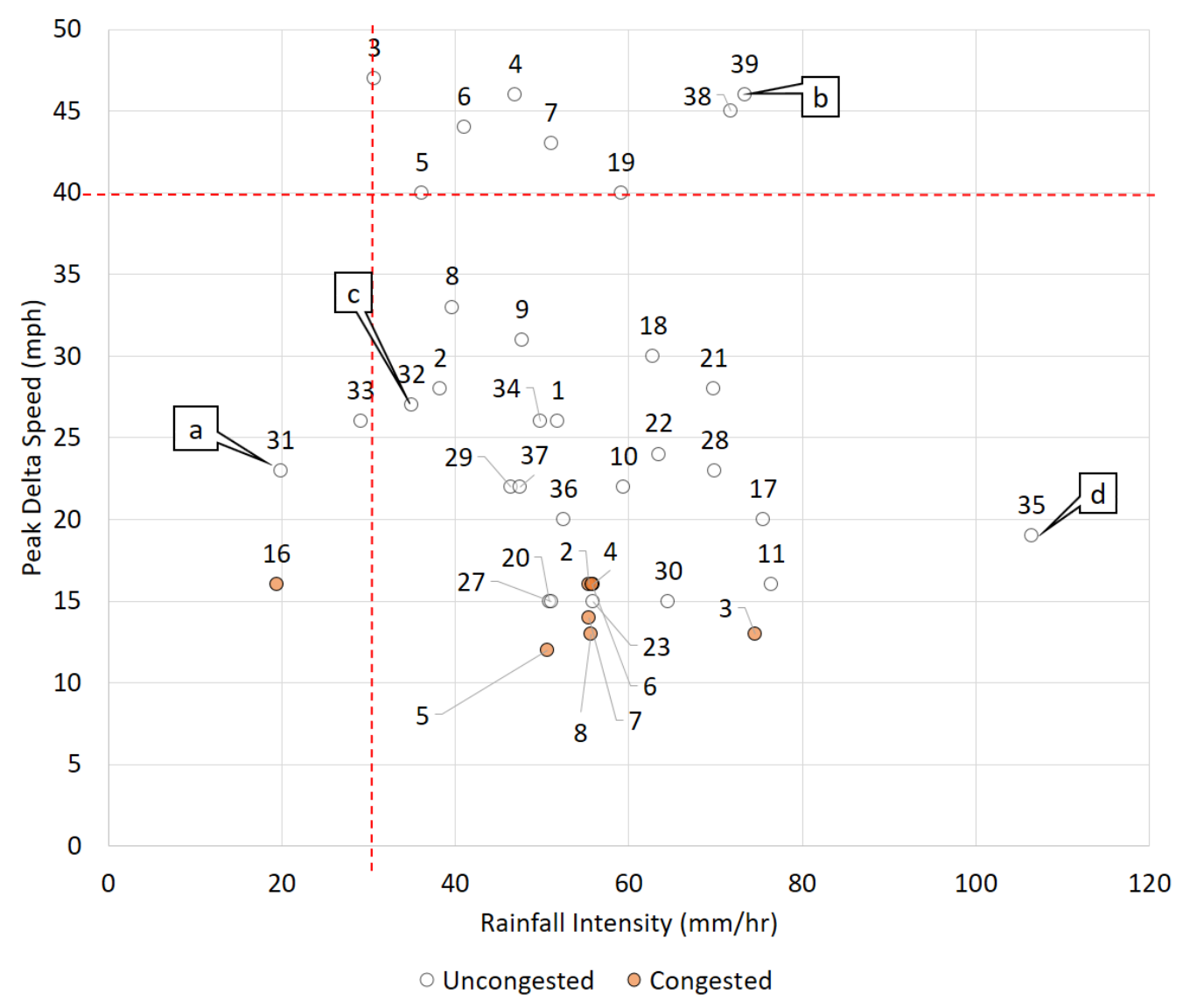

Figure 9. Rainfall rate versus peak delta speed using bilinear interpolation.

\section{RESULTS AND DISCUSSION}

The data from the study suggests that on an uncongested four to six-lane interstate with $12^{\prime}$ wide shoulders, during daylight hours, there was no linear correlation between rainfall intensity and drops in speed. Due to the continuous nature of weather, bicubic interpolation allows data points far from the point of interest to influence the value at that location, resulting in a slightly negative correlation.

The nearest neighbor and bilinear interpolation methods warrant further investigation. Factors affecting speeds during rainfall events can be investigated and compared to see why some types of events saw large drops in speed and other events less so. Figure 10 details a few cases in which it suggests rainfall intensity alone impacted traffic speeds. These are the corresponding events called out with a through d in Figure 9. The bilinear interpolation method was used in these examples. Three callouts (A, B, C) at times before, during and after the storm impact are noted on each time-series graph, with the corresponding radar and traffic map shown. Figure 10a, event \#31, exhibits the lowest rainfall intensity, peaking at $20 \mathrm{~mm} /$ hour but resulting in a $23 \mathrm{mph}$ drop in speed. As is indicated by the radar callouts at A, B, and C, the storm moves across the segment rapidly. Wind gusts could partially explain such a significant drop in speed. Figure 10b, event \#39, exhibits a rainfall intensity up to $73 \mathrm{~mm} /$ hour resulting in a substantial drop in speeds of $46 \mathrm{mph}$. Given the high rates of precipitation and the storm's fast moving nature, the corresponding drop in speed seems to make sense. It is likely that visibility was greatly impaired over the ten minutes 
that the rain remained very close to its maximum intensity. The prolonged intensity of the rain also may have contributed to the longer recovery time shown in the graph, such as lane being partially inundated with water. Figure 10c, event \#32, exhibits a case in which there was relatively steady rainfall over the period of the window with peaks of up to $35 \mathrm{~mm} / \mathrm{hour}$ resulting with a $27 \mathrm{mph}$ drop in speeds. The major drop in speed seems to correspond with the spike in rainfall and may be related to visibility. Finally, Figure 10d, event \#35, exhibits a case in which the speed did not drop very much at $19 \mathrm{mph}$, but the rain intensity was detected to be over $106 \mathrm{~mm} /$ hour. This may be the case that at these high reflectivity conditions, the values can be affected by blockage, biological debris, hail, and other factors could have led to errors in the rainfall estimate. 


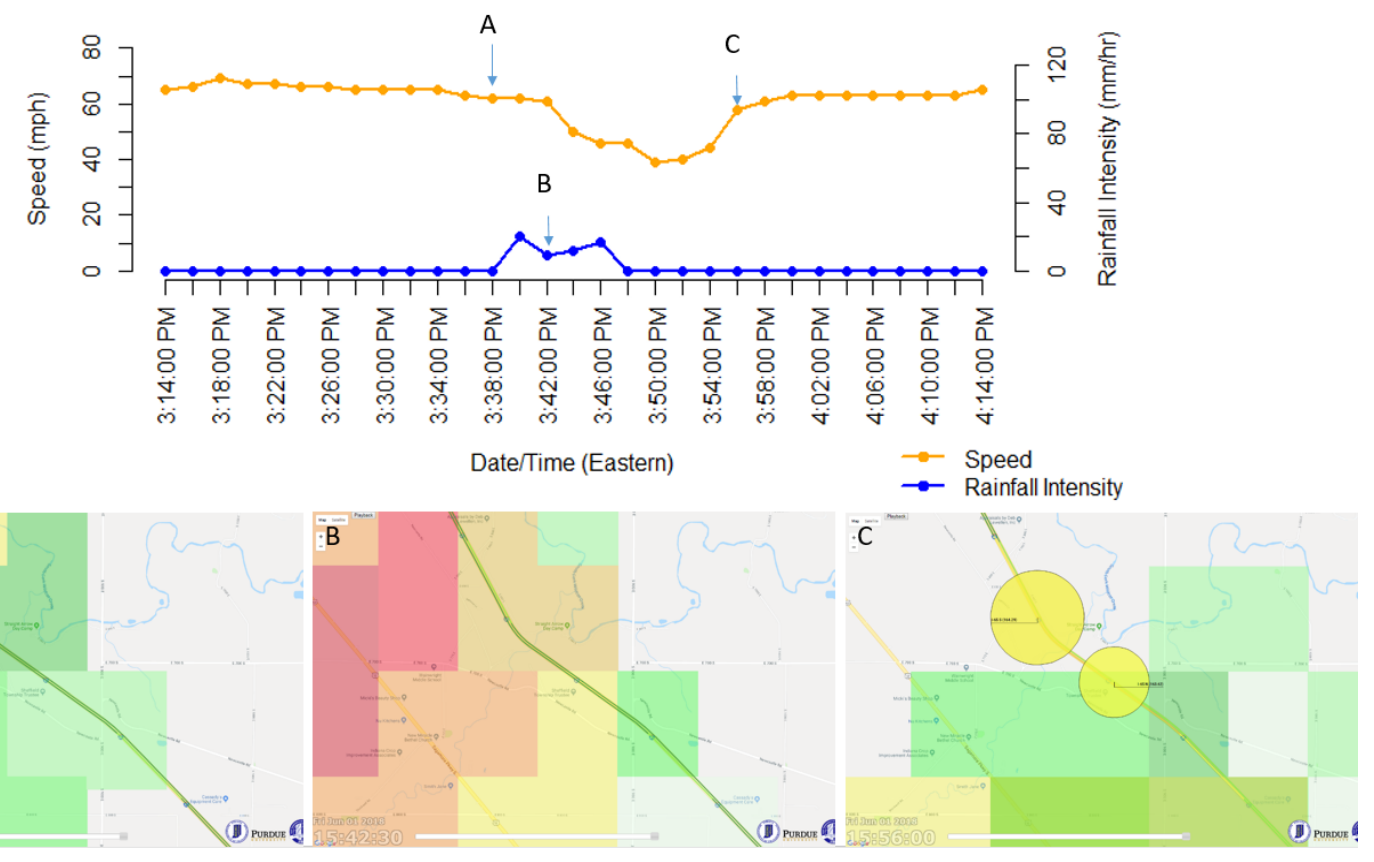

(a) Event 31
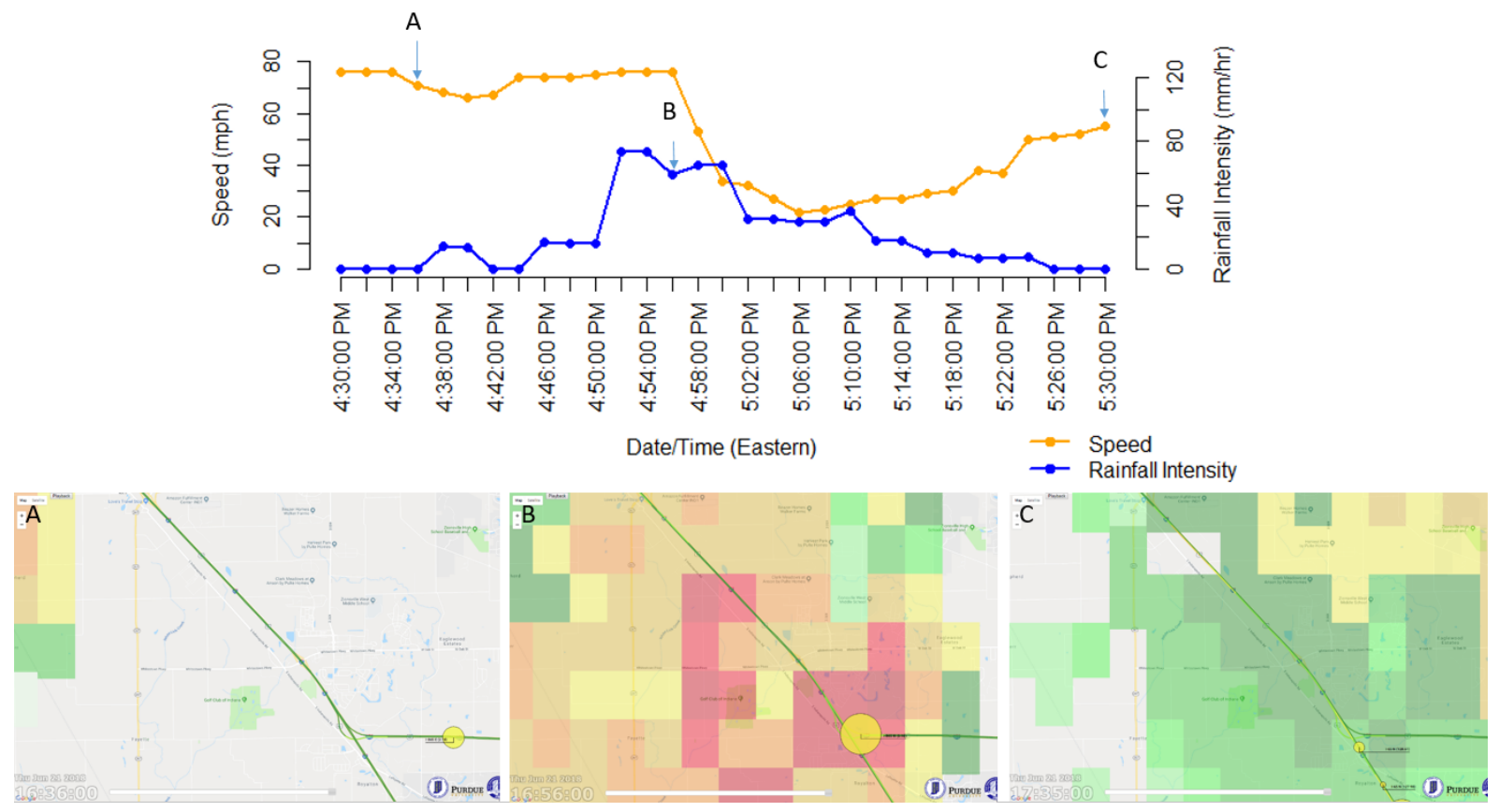

(b) Event 39 

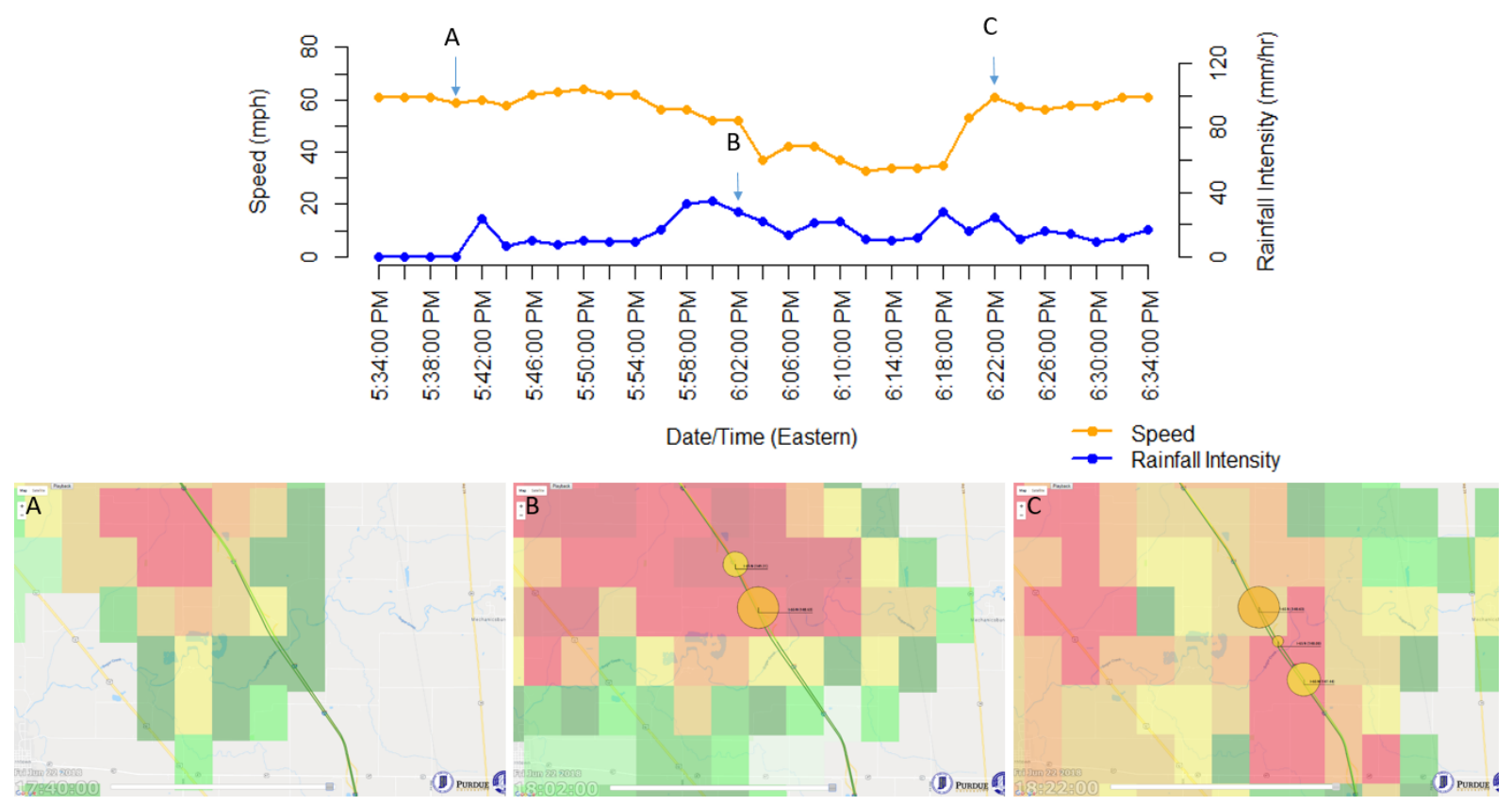

(c) Event 32

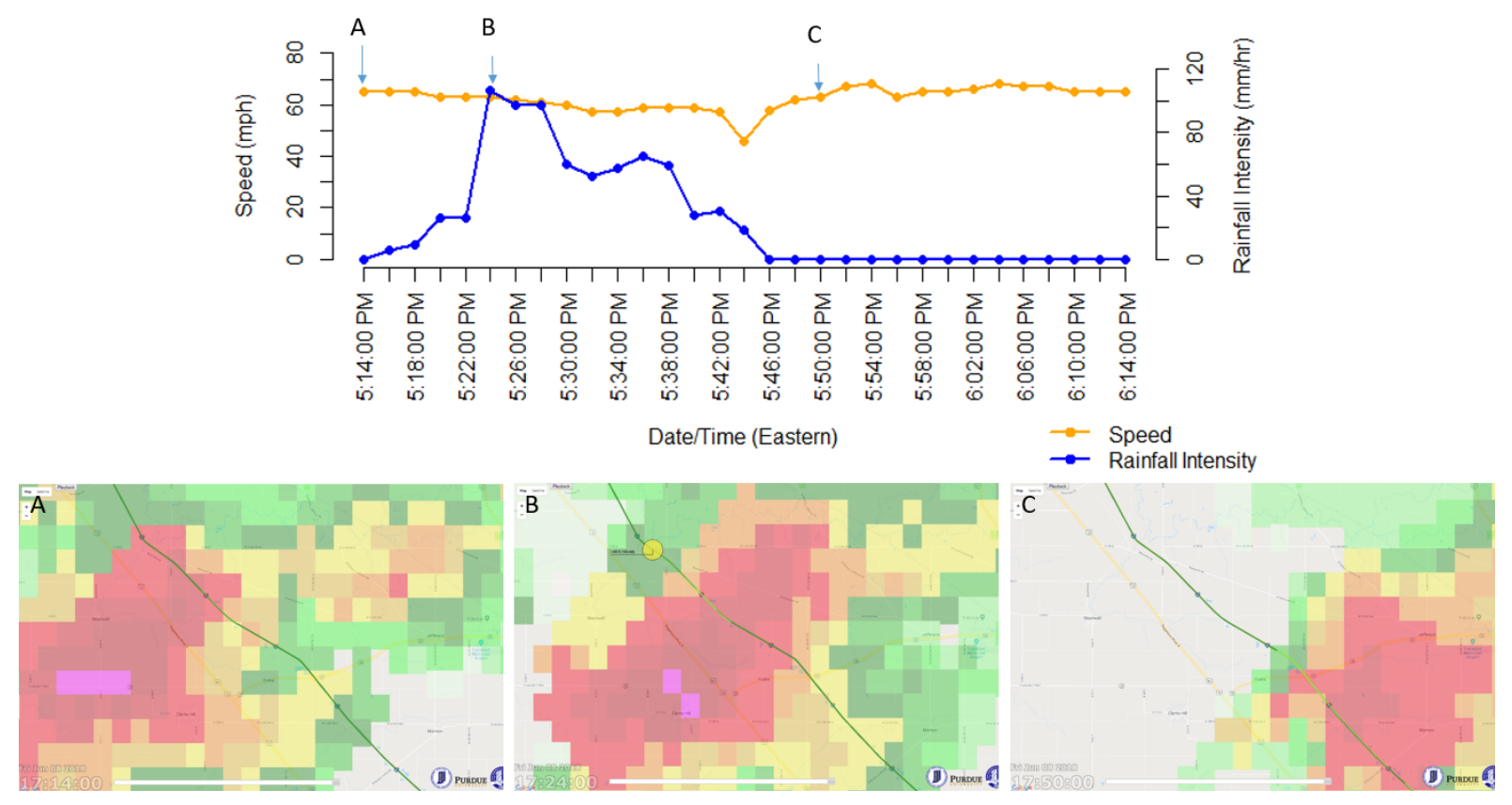

(d) Event 35

Figure 10. Four rain storm use cases overlaying traffic and weather data. 


\section{CONCLUSIONS}

This study investigated the use of high fidelity Doppler data at $1 \mathrm{~km}$ spatial and 2-minute temporal resolution in combination with commercial probe speed data on freeways to assess drops in speeds during rainfall events. One-month of weather data of about 3.3M records on a section of four to six-lane interstate was analyzed. The speed records used were segment-based and reflected the space-mean-speed on the roadways. Previous studies on weather impacts have used point sensors or probe data in urban environments and have mostly used rain data over relatively coarse spatial and temporal fidelities.

Three interpolation methods for estimating rainfall rates were tested and seven metrics were developed for the analysis. Events were generated by triggers from both data sets where uncongested traffic dropped below $50 \mathrm{mph}$ and a corresponding rainfall value was greater than 5.5 $\mathrm{mm} /$ hour. Much more intense localized rainfall amounts than used in previous studies were estimated using the high fidelity data, from $7.6 \mathrm{~mm} /$ hour up to $106 \mathrm{~mm} /$ hour. The bilinear interpolation method for Doppler data was recommended because it detected the greatest number of events and lowest estimated maximum rainfall out of three methods tested, suggesting the method balanced awareness of the weather conditions around the roadway with isolated, localized rain intensities. The nearest neighbor method favored localized, intense storms with higher rainfall estimates, while the bicubic method biased storms that covered a wider area and produced estimates that were less intense.

The key findings were the following:

1. Sharp drops in speed more than $40 \mathrm{mph}$ occurred at rainfall rates of $30 \mathrm{~mm} /$ hour or greater.

2. Beyond estimated rainfall rates over $30 \mathrm{~mm} /$ hour, there were no obvious correlation between rate of rainfall and drops in speed.

3. The average time of first detected rainfall to impacting speeds was 17 minutes.

4. The bilinear method detected the greatest number of events during the 1-month period, with the most conservative rate of predicted rainfall. The range of rainfall intensities were estimated between 7.5 to $106 \mathrm{~mm}$ /hour for the 39 events. This range was much greater than the heavy rainfall categorization at $16 \mathrm{~mm} /$ hour in previous studies reported in the literature.

There are opportunities to expand this research beyond the investigated roadway segments, capacity and periods analyzed. The methods presented provide a scalable technique to estimate and detect speed impact using estimated high-fidelity rainfall data over a large area without human intervention. The difference in reporting time of the weather and speed data will require reconciliation due to driver response, and latency of both systems. In addition, traffic density in the uncongested conditions, percent heavy vehicles, visibility, wind gusts, and standing water in lanes may play a role in speed impact as well. Future studies could aim to isolate these factors further to establish a more precise relationship between rainfall intensity and traffic speed. 


\section{ACKNOWLEDGMENTS}

This work was supported by the Indiana Department of Transportation. The traffic speed data was provided by INRIX. The contents of this paper reflect the views of the authors, who are responsible for the facts and the accuracy of the data presented herein, and do not necessarily reflect the official views or policies of the sponsoring organizations. These contents do not constitute a standard, specification, or regulation.

\section{AUTHOR CONTRIBUTION STATEMENT}

The authors confirm contribution to the paper as follows: conception and design: Downing, Li, Bullock; data collection: Li, McKee; analysis and interpretation of results: Downing, Li; funding acquisition: Bullock; investigation: Downing, Li, Morgan; methodology: Downing, Li; project administration: Bullock; resources: Li; supervision: Li, Bullock; validation: Downing, Morgan, Li; visualization: Downing, Li; draft manuscript preparation: Downing, Li; draft manuscript review and editing: Downing, Li, Bullock.

All authors reviewed the results and approved the final version of the manuscript. 


\section{REFERENCES}

1. How Do Weather Events Impact Roads? Federal Highway Administration. https://ops.fhwa.dot.gov/weather/q1_roadimpact.htm. Accessed July 31, 2018.

2. FHWA Safety Program. Crash Costs for Highway Safety Analysis. Federal Highway Administration. Report No. FHWA-SA17-071, 2018. https://safety.fhwa.dot.gov/hsip/docs/fhwasa17071.pdf. Accessed July 31, 2018.

3. NOAA. Next Generation Weather Radar. NOAA National Centers for Environmental Information. https://www.ncdc.noaa.gov/data-access/radar-data/nexrad. Accessed July 31, 2018.

4. NOAA. MRMS-Multiple Radar/Multiple Sensor. NOAA National Severe Storms Laboratory. https://www.nssl.noaa.gov/news/factsheets/MRMS_2015.March.16.pdf. Accessed July 31, 2018.

5. McCormack, E. and M. E. Hallenbeck. ITS Devices Used to Collect Truck Data for Performance Benchmarks. Transportation Research Record, No. 1957, pp. 43-50, 2006.

6. Lamm, R. D. and S. J. Sprouffske. Integrating Dynamic Vehicle Probe Data into an Advanced Traffic Management System. 14th World Congress on Intelligent Transport Systems 2007, Vol. 1, pp. 48-55, 2007.

7. Sheckler, R. and R. T. McDonough, Using Commercial Vehicle Telematics as a Highway Probe Data Source. 15th World Congress on Intelligent Transport Systems and ITS America Annual Meeting 2008, Vol. 10, pp. 6890-6900, 2008.

8. Zhao, W., E. McCormack, D. J. Dailey, and E. Scharnhorst. Using Truck Probe GPS Data to Identify and Rank Roadway Bottlenecks. Journal of Transportation Engineering, Vol. 139, No. 1, pp. 1-7, 2013.

9. Brennan, T. M., S. M. Remias, G. N. Grimmer, D. K. Horton, E. D. Cox, and D. M. Bullock. Probe Vehicle-Based Statewide Mobility Performance Measures for Decision Makers. Transportation Research Record, No. 2338, pp. 78-90, 2013.

10. NOAA. Automated Surface Observing System (ASOS). NOAA National Centers for Environmental Information. https://www.ncdc.noaa.gov/data-access/land-based-station-data/land-based-datasets/automated-surface-observing-system-asos. Accessed July 31, 2018.

11. Ibrahim, A. T., and F. L. Hall. Effect of Adverse Weather Conditions on Speed-Flow-Occupancy Relationships. Transportation Research Record, Vol. 1457, pp. 184-191, 1994.

12. Brilon, W., and M. Ponzlet. Variability of Speed-Flow Relationships on German Autobahns. Transportation Research Record, Vol. 1555, pp. 91-98, 1996.

13. Rakha, H., M. Farzaneh, M. Arafeh, and E. Sterzin. Inclement Weather Impacts on Freeway Traffic Stream Behavior. Transportation Research Record, No. 2017, pp. 8-18, 2008.

14. Tam, M. L., H. K. W. Lam, B. Chen, K. S. Chan, and S. C. Wong. Using Automatic Vehicle Identification Data for Investigation of Rain Effects on Vehicular Travel Speeds and Travel Choice Behavior. Proceedings of the Conference on Traffic and Transportation Studies, ICTTS, Vol. 322, pp. 944-955, 2008.

15. Stamos, I., J. M. S. Grau, E. Mitskis, and G. Aifadopoulou. Modeling Effects of Precipitation on Vehicle Speed: Floating Car Data Approach. Transportation Research Board, No. 2551, pp. 100-110, 2016.

16. Ivey, D. L., E. K. Lehtipuu, and J. W. Button. Rainfall and Visibility-The View from Behind the Wheel. Journal of Safety Research, Vol. 7, No. 4, pp. 156-169, Dec. 1975.

17. TRB. Highway Capacity Manual: Chapter 11: Freeway Reliability Analysis. National Research Council, Washington, D.C., 2016.

18. Maze, T. H., M. Agarwal, and G. Burchett. Whether Weather Matters to Traffic Demand, Traffic Safety, and Traffic Operations and Flow. Transportation Research Record, No. 1948, pp. 170-176, 2006.

19. Angel, M. L., T. Sando, D. Chimba, V. Kwigizile. Effects of Rain on Traffic Operations on Florida Freeways. Transportation Research Record, No. 2440, pp. 51-59, 2014.

20. Jung, S., X. Qin, D. A. Noyce. Rainfall Effect on Single-Vehicle Crash Severities using Polychotomous Response Models. Accident Analysis and Prevention, No. 42, pp. 213-224, 2010.

21. Omranian, E., et al., Exploring Rainfall Impacts on the Crash Risk on Texas Roadways: A Crash-Based Matched-Pairs Analysis Approach. Accident Analysis and Prevention, No. 117, pp. 10-20, 2018.

22. Li, H., et al., Shock Wave Boundary Identification using Cloud-based Probe Data. Transportation Research Record, Vol. 2526, pp. 51-60, 2015.

23. Mekker, M. M., et al., Characterizing Interstate Crash Rates Based on Traffic Congestion Using Probe Vehicle Data. 2016 Transportation Research Board Annual Meeting, Paper No. 16-1194.

24. NOAA. SHSR-Seamless Hybrid Scan Reflectivity. NOAA Warning Decision Training Division. https://vlab.ncep.noaa.gov/web/wdtd/-/seamless-hybrid-scan-reflectivity-shsr-?selectedFolder=668041. Accessed, July 31, 2018. 
25. AMS. Marshall_Palmer Relation. Glossary of Meteorology. http://glossary.ametsoc.org/wiki/Marshall-palmer_relation. Accessed, July 31, 2018.

26. Akima, H. A. method of bivariate interpolation and smooth surface fitting for irregularly distributed data points. ACM Transactions on Mathematical Software (TOMS), Vol 4, No. 2, pp. 148-159, 1978.

27. Biggerstaff, M. I., \& Listemaa, S. A. An improved scheme for convective/stratiform echo classification using radar reflectivity. Journal of Applied Meteorology, Vol. 39, No. 12, pp. 2129-2150, 2000.

28. Zhang, J., Howard, K., Langston, C., Kaney, B., Qi, Y., Tang, L., and Arthur, A. Multi-Radar Multi-Sensor (MRMS) quantitative precipitation estimation: Initial operating capabilities. Bulletin of the American Meteorological Society, Vol, 97, No. 4, pp. 621-638, 2016. 